NET Institute*

www.NETinst.org

Working Paper

September 2012

\title{
e-Book Platform Competition in the Presence of Two-Sided Network Externalities
}

\author{
Yabing Jiang \\ Lutgert College of Business \\ Florida Gulf CoastUniversity \\ yjiang@fgcu.edu
}

* The Networks, Electronic Commerce, and Telecommunications (“NET”) Institute, http://www.NETinst.org, is a non-profit institution devoted to research on network industries, electronic commerce, telecommunications, the Internet, "virtual networks” comprised of computers that share the same technical standard or operating system, and on network issues in general. 


\title{
e-Book Platform Competition in the Presence of Two-Sided Network Externalities*
}

\author{
Yabing Jiang \\ Lutgert College of Business \\ Florida Gulf Coast University \\ yjiang@fgcu.edu
}

\begin{abstract}
The success of the Kindle e-book platform and the increased popularity of e-books among members of the reading community have attracted extensive interest in the high-tech industry. New platform providers are jumping in the market to compete for device and e-book sales. In this paper, we model the direct competition in the e-book platform market through a two-sided network externality model. We show that publishers can influence consumers' e-book platform adoption decisions and the total e-book sales by strategically deciding the size of contents available on each platform.
\end{abstract}

Keyword: analytical modeling, e-book technology, network externality, platform competition, product differentiation, two-sided market

*Acknowledgement: The author thanks participants at the 45th Annual Hawaii International Conference on System Sciences(HICSS) for helpful comments. This research is funded by the NET Institute (www.netinst.org) whose financial support is gratefully acknowledged. 


\section{e-Book Platform Competition in the Presence of Two-Sided Network Externalities}

\section{Introduction}

With the help of the Internet and e-book technology, the book industry is undergoing a digital transformation. Since contents are now being created digitally thus they no longer need to be printed on paper to distribute to readers. Instead, they can be distributed through various e-book platforms, which are playing an important role in transforming the publishing industry.

While e-book technology has been around for some time, it hadn't changed the mindsets of readers and publishers until Amazon's Kindle emerged. Kindle as an e-book platform offers a new way for book delivery to readers, whereby a digital copy of a book (e-book) is delivered to a reader’s Kindle device. Thus in addition to purchasing a paper book through a physical bookstore or an online store, customers can now purchase a digital book through an e-book platform. When the Kindle device debuted in November 2007 it sold out in five and half hours. Since then new titles and contents are added each week to Amazon’s Kindle platform, contributing to the current collection of over one million book titles. In fact, in the mid of 2010 Amazon’s e-books sales have already surpassed its hardcover sales (Galante and Boudway 2010), and since April 1, 2011 Amazon has sold 105 Kindle books for every 100 print books sold (WSJ 5/20/2011).

The success of the Kindle platform and the increased popularity of e-books among members of the reading community have attracted extensive interest in the high-tech industry. New platform providers are jumping in the market to compete for device and e-book sales. Four years after the debut of Kindle, the e-book platform market is now crowded with multiple players such as Apple’s iPad, Barnes and Noble’s Nook, and Sony’s Reader, etc. Products with similar e-book reader features are being developed by other companies such as Dell, HP, and Google, 
among many others. Increasingly, new and updated e-book devices are loaded with many interactive features such as color, video, note taking, text-to-voice and touch screen capabilities, and publishers have shown growing interests in expanding titles offered and especially the possibility of offering textbooks in e-book format to exploit those interactive capabilities. It seems that finally the book publishing industry is undergoing a digital revolution led by the hightech industry and enabled by the recent development of Internet and e-book technology. According to the AAP Publishers February 2011 Sales Report, e-books rank as the number one format among all book trade categories for the month, and e-books sales were $\$ 90.3$ million, growing 202.3\% vs. February 2010 (Sporkin 2011). The total e-book sales were \$966 million in 2010, and Forrester Research estimated that the number will triple by 2015.

However, research on e-book technology and the transformation in the publishing industry has been sparse (Jiang and Katsamakas 2010 andOestreicher-Singer and Sundararajan 2006). As consumers and publishers adapt to this digital transformation, more research on the competition in this new market as well as the impact of the transformation on channel competition and social welfare is needed. This paper fills the gap and studies the impact of the ebook technology on the book market by examining the e-book platform competition.

The e-book reading devices such as Kindle and Nook are the platforms through which users can access (download) and consume (read) digital books or e-books. Each e-book platform works with dedicated software in order to function as an e-book reader. Another key component of an e-book platformis the e-book store ${ }^{1}$, usually offered by the provider of the corresponding ebook reading device, such as Amazon's Kindle store and Barnes \& Nobel's eBooks store, where e-book device holders can browse and download e-books to their devices through the installed

\footnotetext{
${ }^{1}$ While an e-book platform includes the e-book reading device, the online e-book store, and the corresponding ebook software, we use e-book reading device and e-book platform interchangeably as an e-book platform provider is more interested in boosting the device sales to make its platform the dominant choice.
} 
software. In summary, there are two markets involved in the e-book business: the e-book reading device market and the e-book content market. Consumers need to purchase an e-book reading device first (or install required software to PCs or other portable devices) and through the dedicated reading devicesthey can then download and read e-books.

We consider three groups of players in the e-book market: readers (consumers), publishers and authors as content providers, and e-book platform providers. In a general book supply chain, authors and publishers are two different entities. But since they share the same objective of selling more contents, we model them as one entity in this paper, ignoring the profit sharing between them, to focus on the e-book platform competition. In addition, we model ebook platforms as independent intermediaries since they are often owned by non-publisher third parties, which have the financial, marketing and technology strengths and forward thinking business vision of digital transformation in the publishing industry.

In general, publishers usually own copyrights of book titles both in print and digital forms, though increasingly authors are more likely to negotiate these two separately with publishers in response to the current transition to e-books in the publishing industry. In addition, publishersoften decide what titles appear on e-book platforms and on which e-book platform(s). As readers need to consume e-books through a particular e-book platform, the e-book market is best characterized as a two-sided market, device and content, with network externalities.

In this two-sided market, an e-book platform provider acts as the middleman through which readers interact with content and publishers sell to readers. The popularity of an e-book platform attracts publishers to offer more e-book titles in the corresponding e-book store whereas a wide collection of titles in an e-book store makes the corresponding e-book platform more attractive to readers. In contrast to traditional paper-book retailers, the e-book platform providers 
make a profit from selling the e-book devices to readers, in addition to taking a cut on each ebook sale. Thus they possess more market power over the publishers as more readers adopt their platforms.

Platform provider as an intermediaryin the e-book market has to make strategic decisions such ashow much to charge for the reading devices and whether to make its e-book platform compatible with other e-book providers' platforms.A publisher has to decide whether to offer an e-book version of a title and on which e-book platform(s),and it also needs to decide how much to charge for the e-book. In this paper, we study the competition in the e-book platform market,considering the two-sided network effect. We focus on the direct competition between two e-book platforms. We investigate publishers' choices in distributing e-books through the platforms andstudy the widely adopted agency content pricing model ${ }^{2}$, in which publishers make the content pricing decision and charge the same content price across platforms.

The remainder of the paper is structured as follows: Section 2 reviews related literature. Section 3 presents the competition model between two e-book platforms and section 4 analyzes the e-book market equilibrium. Section 5concludes the paper with discusses of results and future research.

\section{Literature review}

The subject of e-books has recently been studied in Oestreicher-Singer and Sundararajan (2006) and Jiang and Katsamakas (2010).The first paper studies e-book pricing and its impact on physical goods sales. It examines the influence of digital rights management and piracy on ebook pricing in a monopoly model. The second paper also focuses on the e-book industry

\footnotetext{
${ }^{2}$ In another content pricing model, the wholesale pricing, first adopted by Amazon, the content pricing decisions are made by platforms. Under the wholesale pricing model, platforms compete directly in both the device and content market. Here we study the agency pricing model since it is currently adopted in practice.
} 
andstudies the direct competition between paper book retailers and an e-book seller while incorporating paper book and e-book market asymmetry in the model. But it takes a different approach and mostly examines the impact of e-book technology on the book market, especially how factors such as ownership of the e-book seller, market asymmetry, price power of book sellers, and consumers' preferences for e-books affect the strategic interaction in the book market and total book readership. While both works pioneer research on e-book technology and its impact on the book industry, however they do not treat the e-book format and technology as a new platform and thus do not consider the impact of network externality in the e-book market.

Because we model the e-book market by incorporating its network externality features thus this paper is closely related to network externality literature. Katz and Shapiro (1985) are among the first to study the effect of direct network externality on competition and market equilibrium. Direct network externality exists in industries whereas consumer value of a product grows with the size of the product network, and this subject is further studied in numerous literatures. For example, Farrell and Saloner (1986) examine the effects of compatibility and installation base on new entrants, and Katz and Shapiro (1986) study the possible adoption outcomes of proprietary technologies with and without technology sponsorship in the presence of network externality. Xie and Sirbu (1995) further examine the duopoly competition with an incumbent and a new entrant, incorporating network externality and compatibility in a dynamic pricing model. Conner (1995) also examines when an incumbent should encourage an entrant in the presence of network externality but assumes that the incumbent's products are of higher quality than the entrant's. These papers,however, only study one side of the market with direct demand network externality and do not consider the other side of the market with indirect 
network externalities. Because the e-book market exhibits two-sided network externalities we have to consider both sides of the market and incorporate the indirect network externality.

Rochet and Tirole (2006) summarize prior works on two-sided markets. They define the key concepts of usage externalities and membership externalities and report two popular models used to study two-sided markets in a monopoly setting: one focuses on pure usage externalities and the other on pure membership externalities. They also present a canonical model integrating the usage and membership externalities. Parker and Van Alstyne (2005) analyze a market with two-sided network externalities. Their focus is on explaining why a firm may subsidize one side of the market, and they do not consider competition between networks. Economides and Katsamakas (2006) study the optimal two-sided pricing strategy of a platform firm. Their main focus is to analyze the corresponding pricing strategy of a proprietary platform and an open platform and compare the pricing, profitability, product variety, and social welfare outcomes between the two platforms. They only briefly look at the competition between an open platform and a closed platform.

Rochet and Tirole (2003) model two-sided markets such as the credit card market where the platforms mostly only impose per-transaction based charges on both sides (pure usage externalities). They focus on the price competition between two platforms and derive and compare the corresponding pricing equilibrium when the platforms are for-profit (proprietary) and not-for-profit (owned by members). Armstrong (2006) instead studies competition between two platforms in a pure-membership-externality model and with a different agent utility function and fee structure by the platforms. He focuses on analyzing the equilibrium prices for the “competitive bottlenecks” case in which agents from one side of the market choose singlehoming and agents from the other side choose multi-homing. He shows that in equilibrium 
platforms offer low prices to the single-homing side to compete for their business but they exert monopoly power by charging high prices to the multi-homing side. In both models, two platforms engage in price competition and are horizontally differentiated following the Hotelling specification. Caillaud and Jullien (2003) also study the price competition between two platforms and consider that users may choose multi-homing, but they model platforms offering imperfect matching service to two homogeneous user groups and use a different pricing structure whereas the platforms charge users a registration fee upfront and a transaction fee that is contingent on a match. Because their model setting is different from Armstrong (2006), it is possible that in equilibrium users may choose global multi-homing in which all users choose multi-homing. They find similar results as in Armstrong (2006) that the single-homing side is treated well relative to the multi-homing side and exclusiveness (single-homing only) intensifies the competition between the two platforms.

The above works on two-sided markets all assume that the agents of the two sides join the market at the same time and therefore focus on the simultaneous coordination game. Hagiu (2006) instead offers a different treatment of the two-sided market issue by studying the case whereas agents of one side of the market join first. Following Caillaud and Jullien’s (2003) solution and equilibrium concept, he investigates whether in equilibrium the platform(s) should commit to the price charged to the side arriving late when trying to attract the side arriving earlier in both a monopoly and a duopoly setting.

To summarize, prior literature on two-sided market often focuses on the pricing strategy of a single platform with a minimum treatment on competition (Parker and Van Alstyne 2005, Economides and Katsamakas 2006, and Rochet and Tirole 2006). For works that do consider platform competition, they either assume no differentiation (Caillaud and Jullien 2003 and 
Hagiu2006) or a horizontal differentiation between two platforms (Armstrong 2006 and Rochet and Tirole 2003). In the e-book market, however, platforms offer different reading device and software features and thus are often perceived as of different qualities. Here, we contribute to current two-sided network externality literature by studying the direct competition between two vertically differentiated platforms in the presence of network externality. We derive the equilibrium prices and market shares in the e-book platform market and evaluate the impact of the size of contents on platform competition. We also examine how the publishers can strategically influence the total e-book sales through their platform adoption decisions.

\section{The model}

In this section, we model the direct competition between two e-book platforms, taking into consideration the two-sided network externality effect.

We observe that the e-book market shares the same nature with some other two-sided markets where members of one side of the market often arrive before members of the other side. For example, in software and video game markets most application and game sellers join platforms before most buyers do. Similarly, e-book platforms need to get the publishers on board first in order to attract readers. Hence, instead of modeling this two-sided market as a simultaneous coordination game, following Hagiu (2006) we focus on the strategic issues in this two-sided market in which publishers commit first, agreeing to offer a certain number of titles on ane-book platform. Hagiu (2006) studies the pricing equilibrium in a two-sided market with a monopoly platform and duopoly platforms, given that sellers join the market first. In his model, the platform sells to buyers and charges sellers for using the platform. The buyers in his model correspond to the readers in our model, and the sellers in his model correspond to publishers in 
our model.He focuses on sellers' coordination issues, considering that platforms may commit to prices charged to buyers when announcing prices for sellers. In addition, the duopoly platforms engage in a Bertrand competition. Different from Hagiu (2006), we examine platform competition between two vertically differentiated platforms and focus on buyers' platform adoption decisions, given that publishers have already made commitments to each platform.

In two-sided market literature, a platform either charges both sides fixed membership fees or usage fees, or sometimes a combination of both, see Armstrong (2006), Caillaud and Jullien (2003), Rochet and Tirole (2003) and (2006). These works also focus on individual buyer and seller's utility functions to derive the network size on each side whereas other researchers (Economides and Katsamakas 2006 and Parker and Van Alstyne 2005)work with a predefined aggregated demand function for each side. Here, to better convey the characteristics of the ebook market we take an integrated approach, deriving platforms' market demands for devices from individual readers' utility functions and using the aggregated demand function in the content market. Next, we first look at the competition in the e-book device market and then analyze the e-book content consumption to derive some insights for the publishing industry.

\subsection{E-book device market}

Suppose there are two competing e-book platforms 1 and 2 in the e-book market. Readers perceive the two platforms, either the reading devices or a combination of the reading device and e-book software, are of different qualities. Let $q_{i}$ be platform i's quality perceived by readers and $P_{i}$ and $c_{i}$ be the price and marginal cost of i's reading device, where $\mathrm{i}=1,2$. Without loss of generality, we assume that $q_{2}>q_{1}$ and $c_{2}>c_{1}$, and we focus on the nontrivial case in which the high quality platform charges a higher price for its devices $\left(P_{2}>P_{1}\right)$. 
Let $D_{i}$ be the demand for platform i's devices and $N_{i}$ be the number of titles available on platform i. Following vertical differentiation literature, we assume readers are of different types as they have different valuations for quality. We use $\theta$ to represent a reader's type and assume $\theta$ is uniformly distributed in [- A, 1] with unit density (Katz and Shapiro 1985 and Conner 1995). A reader's net valuation for platform i's device $u_{i}(\theta)$ is given by equation (1):

$$
u_{i}(\theta)=\left(\alpha N_{i}+\theta\right) q_{i}-P_{i} .
$$

Here, a reader's valuation for a platform increases not only with the platform quality $q_{i}$ but also with the size of content $N_{i}$ that is available on the platform. This is because a higher $N_{i}$ means a broader selection of titles from which readers can choose and thus the size of content available on a platform enhances readers' valuation of the platform. The $\alpha N_{i}$ term captures the network externality where parameter $\alpha$ represents the marginal effect on a reader's valuation for an additional title added to platform $\mathrm{i}$. When everything else is the same, a reader with a high valuation on quality realized a high net utility. Thus, only readers with $u_{i}(\theta) \geq 0$ will consider purchasing a reading device and they will choose the platform that produces a higher net valuation.

The type of readers who are indifferent between choosing platform $i$ and not participating is given by $\theta_{i}=\frac{P_{i}}{q_{i}}-\alpha N_{i}$, where $u_{i}\left(\theta_{i}\right)=0$, and the type of readers who are indifferent between the two platforms is given by $\tilde{\theta}=\left[P_{2}-P_{1}+\alpha\left(N_{1} q_{1}-N_{2} q_{2}\right)\right] /\left(q_{2}-q_{1}\right)$, where $u_{1}(\tilde{\theta})=u_{2}(\tilde{\theta})$. Given that $P_{2}>P_{1}$ and $q_{2}>q_{1}$, the two platforms are more likely to coexist when $N_{2}<N_{1}$ (i.e., platform 2 does not have all the advantages over platform 1). If the two platforms coexist in the market, it must be that readers of high $\theta$ type choose platform 2; readers of medium $\theta$ type choose platform 1; and readers of low $\theta$ type choose not to participate in the market. 
Accordingly, the demand for platform 1's devices is $D_{1}=\tilde{\theta}-\theta_{1}$ and the demand for platform 2's devices is $D_{2}=1-\tilde{\theta}$, subject to the parameter condition $1>\tilde{\theta}>\theta_{i}$.

\subsection{E-book content market}

Next, consider the content side of the market. Following information goods literature, we assume that the platforms' and publishers' marginal cost of selling e-books is zero ${ }^{3}$. In addition, we assume that publishers have committed to the two platforms by providing $N_{1}$ and $N_{2}$ titles on platforms 1 and 2, respectively. As the owners of digital contents, major publishers currently adopt the agency pricing model in which they charge a uniform price $P_{c}$ across platforms for each e-book download (Trachtenberg and Bray 2010 and Trachtenberg 2011).

Since readers who adopt a reading device will often consume multiple e-book titles and have diverse interests in titles, we do not consider each individual publisher or book title but rather focus on aggregated content sales in the e-book market. We assume that each platform keeps $r$ share of its e-book sales. This is equivalent to the typical two-sided market model in which a platform charges readers a fixed fee $P_{i}$ (price for the device) for accessing the platform and it charges publishers a fixed fee $r P_{c}$ for each e-book download whereas readers pay $P_{c}$ to publishers (through platforms) for each e-book download.

Prior literature on two-sided markets often assumes a multiplicative demand function for transactions between the two sides (Caillaud and Jullien 2003, Rochet and Tirole 2003 and 2006). Following that assumption and using the notations in this article, the e-book sales would be $D_{i} N_{i}$ for platform i. Here, we follow the same multiplicative assumption but also consider the impact of price and readers' budget and time constraints on total e-book sales. Given the content

\footnotetext{
${ }^{3}$ Publishers need to pay authors a royalty fee for each e-book transaction. Since we model publishers and authors as one entity we do not consider the profit sharing between them here, even though adding a royalty fee does not change any of the outcomes of the paper.
} 
size $N_{i}$, let $Q_{i}=f_{i}-b P_{c}$ be the content demand function for platform i, where $f_{i}=D_{i} g\left(N_{i}\right)$ and $g(\cdot)$ is a function that satisfies $g(\cdot)>0, g^{\prime}(\cdot) \geq 0$ and $g^{\prime \prime}(\cdot) \leq 0$ for $N_{i}>0$. Here, content consumption on a platform increases in the size of available contents $N_{i}$ and the size of the platform's device market $D_{i}$, but it decreases in the content price $P_{c}$. The term $f_{i}$ represents the demand for e-books at $P_{c}=0$, and the $g(\cdot)$ function represents the content consumption of each additional reader of the platform. In reality, a reader will not consume every title available on the platform, even if all e-books are free, because readers have limited time available for reading. Since readers often have a budget and time constraint, it is reasonable to use $g\left(N_{i}\right)$ instead of $N_{i}$ in the $f_{i}$ term, and we can think of $g\left(N_{i}\right)$ as the average content consumption for readers of platform i, given the content size $N_{i}$. This average content consumption will be non-decreasing in the size of content $\left(g^{\prime}\left(N_{i}\right) \geq\right.$ 0 ). It is typical that the average content consumption increases as publishers start adding titles to a platform. But as more and more titles are added to the platforms, readers are running out of free time for reading, even without considering their budget constraints. Thus it is reasonable to assume that readers' average e-book consumption is bounded from above and hence the assumptions of $g^{\prime}\left(N_{i}\right) \geq 0$ and $g^{\prime \prime}\left(N_{i}\right) \leq 0$.

Different from prior literature, we separate a reader’s consumption decision for devices from her consumption decision for contents due to the characteristics of this two-sided market. A reader's decision to purchase a reading device is a one-time event, and it is mostly driven by the quality of the platform, which includes all device and software features, and the total size of available contents, which affects the reader's ex ante overall valuation of the platform. A reader's decision for content consumption is, however, ex post, and is an ongoing process involving a tradeoff between the reader's money/time and her valuation on the individual title of interest at the time of each e-book purchase. Thus it makes sense to separate the two. 


\section{Equilibrium analysis}

We analyze the two-sided market equilibrium under the agency content pricing model in this section. This platform competition game can be depicted as a two-stage game. In the first stage, publishers negotiate with each platform, and as a result they commit $N_{i}$ titles to platform i and share $r$ fraction of e-book sales with the corresponding platform. Under the agency pricing model, the publishers decide the uniform price $P_{c}$ for each e-book download to maximize their profit function given by equation (2):

$$
\pi_{c}=(1-r) P_{c}\left(f_{1}-b P_{c}+f_{2}-b P_{c}\right)
$$

In the second stage, given the content price $P_{c}$ and publishers' commitment of contents, the two platforms will simultaneously determine the prices of their devices to maximize their combined profits from the device and content markets. The platforms’ profit functions are characterized in equations (3) and (4):

$$
\begin{aligned}
& \pi_{1}=\left(P_{1}-c_{1}\right)\left(\tilde{\theta}-\theta_{1}\right)+r P_{c}\left(f_{1}-b P_{c}\right) \\
& \pi_{2}=\left(P_{2}-c_{2}\right)(1-\tilde{\theta})+r P_{c}\left(f_{2}-b P_{c}\right) .
\end{aligned}
$$

We use backward induction to solve the pricing equilibrium in this two-sided market. We first solve the equilibrium device prices with content price $P_{c}$ as given. Then we take the equilibrium device prices back into equation (2) to solve the equilibrium price for content. We treat $N_{i}, g(\cdot)$, and $r$ as exogenous in this model. Proposition 1 describes the equilibrium content price, the equilibrium device prices, and the equilibrium market share for each platform. All proofs are presented in the Appendix. 
Proposition 1 (Pricing equilibrium in the e-book content and device markets): When two platforms (1 and 2) compete in the device market and publishers adopt the agency pricing model, at equilibrium the publishers set the optimal content price at $P_{c}^{*}=\left[g\left(N_{1}\right) q_{2} T_{1}+g\left(N_{2}\right) q_{1} T_{2}\right] /$ $T_{3}$, and the platforms' device prices and market demands are as follows:

$P_{1}^{*}=\left[T_{1}+c_{1}\left(4 q_{2}-q_{1}\right)-2 d_{1}^{*} q_{2}-d_{2}^{*} q_{1}\right] /\left(4 q_{2}-q_{1}\right)$,

$P_{2}^{*}=\left[T_{2}+c_{2}\left(4 q_{2}-q_{1}\right)-2 d_{2}^{*} q_{2}-d_{1}^{*} q_{2}\right] /\left(4 q_{2}-q_{1}\right)$,

$D_{1}^{*}=q_{2}\left(T_{1}+2 d_{1}^{*} q_{2}-d_{1}^{*} q_{1}-d_{2}^{*} q_{1}\right) /\left[q_{1}\left(q_{2}-q_{1}\right)\left(4 q_{2}-q_{1}\right)\right]$, and

$D_{2}^{*}=\left(T_{2}+2 d_{2}^{*} q_{2}-d_{1}^{*} q_{2}-d_{2}^{*} q_{1}\right) /\left[\left(q_{2}-q_{1}\right)\left(4 q_{2}-q_{1}\right)\right]$, where $d_{1}^{*}=r P_{c}^{*} g\left(N_{1}\right)$, and $d_{2}^{*}=$ $r P_{c}^{*} g\left(N_{2}\right)$ and the values of $T_{1}, T_{2}$, and $T_{3}$ are defined in the Appendix.

Here, we present the optimal platform prices and platform market shares in the simpler form, which contains the optimal content price $P_{c}^{*}$ in the $d_{i}$ terms. At the market equilibrium, a platform's device price is a function of the content price charged by the publishers. This is because part of a platform's profit is coming from content sales on its devices. As readers' demand on content is sensitive to the content price and the content demand on a platform is also directly related to the device demand, thus the platforms' profits are affected by content price as well. When making their platform pricing decisions both platforms will take into consideration the impact of content price on their direct competition in the platform market. For publishers, in addition to the content price, total content demand also critically depends on the total demand in the platform market since readers need a reading device to access e-books. As publishers commit first, when making their content pricing decision they will take into consideration the impact of content price on the device market, reflected in the content demand function. Proposition 1 shows that a platform's device price decreases in content price. This can be explained by 
examining the platform's first-order condition. At the equilibrium, the marginal benefit from a marginal increase in the device price equals the corresponding marginal loss in the device and content sales. When everything else is the same, a higher content price corresponds to a bigger loss in content sales. Thus the equilibrium device price is lower at a higher content price. Because of this direct connection between content and device prices, any market parameters that influence the content price will also directly affect device prices in the platform market.

Proposition 2 describes how the equilibrium content price and platform prices change with a few market parameters. To simplify the notation, we assume that $g\left(N_{1}\right) \approx g\left(N_{2}\right)=g$ from now on. Recall that $g(\cdot)$ represents a reader's average content consumption and it is nondecreasing in the size of content available on the corresponding platform. Since $g(\cdot)$ is a function of the content size only and it is not affected by the parameters considered in Proposition 2, without loss of generality this assumption only simplifies the notations and makes it possible to directly compare the impact of parameters on the two platforms. This assumption can be justified as follow. As we discussed earlier, readers are constrained by the time and budget available for reading and hence $g(\cdot)$ tends to be stable when more contents are available. In such cases, even though $N_{2}<N_{1}$, the average consumption per reader of platform 1 is not necessarily higher than that of platform 2. That is, as the size of content increases readers of the two platforms have similar average content consumption. ${ }^{4}$ By examining the comparative statics, we find the following outcomes in Proposition 2.

\section{Proposition 2A (Impact of market parameters on content price):The equilibrium content} price: (i) increases in readers' network externality parameter $\alpha$ and the publisher-platform

\footnotetext{
${ }^{4}$ A further discussion of this $g\left(N_{1}\right) \approx g\left(N_{2}\right)=g$ assumption is provided when we evaluate the impact of publishers' content size decisions under Proposition 3.
} 
profit sharing parameter $r$; and (ii) decreases in readers' content price sensitivity parameter $b$ and platforms' marginal device cost $c_{i}$.

Proposition 2B (Impact of market parameters on platform prices):At equilibrium, a platform's device price: (i) increases in readers' content price sensitivity parameter b but the price of the high quality platform is more sensitive to the changes in parameter b; (ii) increases in its marginal device cost $c_{i}$ but the price of the low quality platform is more sensitive to the changes in its marginal device cost; (iii) decreases in the publisher-platform profit sharing parameter $r$ but the price of the high quality platform is more sensitive to the changes in parameter $r$.

It is not a surprise that the equilibrium content price decreases when readers are more price sensitive (parameter $b$ increases) and it increases when publishers have to share more profit with the platforms (parameter $r$ increases). But because of the two-sided network externalities, here the change in the equilibrium content price also reflects the impact of a change in parameter on the platform prices. A change in readers' content price sensitivity parameter $b$ or the profit sharing between publishers and platforms $(r)$ directly affects content demand or publishers profit margin. But changes in these parameters also have a direct impact on platform prices and hence platform demands because part of the profit for each platform comes from content sales. As the content demand ties to the demand in the platform market because of the two-sided effect, thus the change in the equilibrium content price also captures the indirect effect from the platform market due to a change in $b$ and $r$.

Specifically, because increasing parameter $b$ has a negative direct effect on content price, in terms of platforms' first-order condition this corresponds to a lower marginal loss from a 
marginal change in the platform price and thus in response platforms' device prices increase in parameter $b$ (Proposition 2B(i)). This change in device price translates to a lower device demand, which further lowers content sales. As a result, the negative impact of parameter $b$ on content price is amplified due to the two-sided effect. As for the profit sharing parameter $r$, because part of the platforms' profits are from content sales, in terms of platforms' first-order conditions a higher $r$ corresponds to a higher loss in profit due to a marginal change in device price and thus determines a lower device price in response (Proposition 2B(iii)).Without the twosided effect, content price is independent of the profit sharing parameter $r$. But since the content demand ties to the total device demand, which is indirectly affected by the profit sharing parameter $r$ through platform prices, as a result content price increases in the profit sharing parameter $r$.

A higher network externality parameter $\alpha$ means readers have a higher net valuation on a platform, which corresponds to a higher device demand while everything else is the same. To further benefit from this increased demand in device market and thus content sales, publishers will increase content price. Naturally, device prices increase in the marginal device costs, and higher device prices reduce the total device demand, which negatively impacts the total content demand. In respond to this two-sided negative effect from the marginal device cost, publishers will decrease their content price. However, this negative effect of marginal device cost on content price mitigates some of the positive effect of marginal cost on device price. As a result, device prices increase less due to the two-sided effect from the content market.

Next, we further evaluate the impact of publishers' content allocation decision on the market equilibrium. 


\section{Proposition 3A (Effect of the size of content on the content market):(i) Content price}

increases in the size of content on either platform, and adding a title to the low quality platform is twice as effective in increasing content price as adding a title to the high quality platform ; (ii) the total content consumption increases in the size of content on either platform, and adding a title to the low quality platform is twice as effective in increasing total content consumption as adding a title to the high quality platform;(iii) publishers' profit increases in the size of content on either platform, and adding a title to the low quality platform is twice as effective in increasing publishers' profit as adding a title to the high quality platform.

Proposition 3B (Effect of the size of content on the platform market):(i) Readers' demand for a platform's devices increases in the size of content available on that platform but decreases in the size of content available on its rival's platform, specifically, $\frac{D_{1}}{N_{1}}>\frac{D_{2}}{N_{2}}>0$ and $\frac{D_{1}}{N_{2}}<\frac{D_{2}}{N_{1}}<0$; (ii) the total device demand increases in the size of content on either platform, and adding a title to the low quality platform is twice as effective in increasing total device consumption as adding a title to the high quality platform.

The results of Proposition 3 are derived under the assumption $g\left(N_{1}\right)=g\left(N_{2}\right)=g$, which implies that on average a reader consumes the same amount of content regardless of her platform decision. This assumption holds when the sizes of content on both platforms are big enough. In such cases, a reader's total content consumption does not change when new titles are added to a platform due to her time and budget constraints. However, the reader's net valuation for the platform (equation (1)) increases as there are more titles to choose from. This assumption explicitly neutralizes the impact of content size on individual reader’s average content consumption and hence the direct effect of content size on content sales for each platform. This 
enables us to further examine the intricate effects of change in content size on content price, device and content demand, and publishers’ profit.

First, when everything else is the same, an increase in the content size on a platform makes that platform more attractive to consumers and that leads to more sales in the device market. As more readers adopt an e-reading platform, the total content consumption increases, even though the simplified assumption neutralizes the impact of content size on individual reader's average content consumption. Thus increasing content size on a platform indirectly increases the total content consumption.

When the content price is optimally determined, because the total content demand increases due to the indirect effect of an increase in the size of content on a platform, the optimal content price determined by the corresponding first-order condition increases. Moreover, content price increases more with the size of content on platform 1 than that on platform 2 . Thus the impact of content size on publishers' profits comes from two parts: a direct change in the content price and an indirect change in content demand. We find that a change in content size has equal impact on these two parts. As both the content price and total content consumption increase in content size, publishers’ profit increases in content size as well. Again, adding more titles to platform 1 is twice as effective in increasing publishers’ profit as adding more titles to platform 2.

Here, increasing the size of content available on one platform increases the device demand for that platform but decreases the device demand for its rival's platform. This positive effect of the size of content on a platform's own device demand is stronger for platform 1 than platform 2 whereas the negative effect of the size of content on one's rival's device demand is stronger for platform 2. Together the net effect of adding a title to a platform on the total device 
demand is positive, but adding a title to platform 1 is twice as effective to boost the total device ownership as adding a title to platform 2. Given that readers need a reading device to consume ebooks, having more readers adopt an e-book platform, either platform 1 or 2 , is within the common interest of all publishers. Hence publishers may strategically make more titles available on the low quality platform 1 than the high quality platform 2 to further boost the total device ownership and the total e-book sales due to the two-sided network effect.

\section{Conclusion and future work}

As readers, overwhelmed by the value-added features provided by e-book platforms, quickly adopt the e-book format, publishers are gradually becoming supportive of this digital transformation. The e-book platform market is now the new battle field for firms. Technology companies such as Amazon and Apple are quickly emerging as the leading players in the platform market, each offering some devices with unique features and targeting different customer segments (Galante and Boudway 2010 and Peers 2010). Our platform competition model conveys the unique features and network externalities exhibited in the e-book platform market. The analysis provides some guidelines for publishers on how to better navigate through the digital transformation. Due to the two-sided network effect, publishers' commitments to ebook platforms in terms of total contents available on a platform are critical to consumers’ platform adoption decisions and the total size of the e-book device market.

Our results suggest that as e-books and e-book platforms become widely accepted by consumers and publishers and more titles are available on the e-book platforms, price of e-books will increase over time. We find that increasing the profit sharing with platforms in the content market intensifies the price competition in the platform market whereas increased reader content 
price sensitivity relaxes the price competition in the platform market. In addition, as the marginal costs of the e-reading devices decrease over time due to technology improvement, the device prices will decrease whereas the content price will increase. Other than responding to market changes, publishers can help maximize consumers' e-book platform adoption rate and thus the total e-book sales by strategically controlling the size of contents available on each platform. Specifically, making more contents available on the low quality platform is more effective in increasing the total e-book sales and the total e-book platform adoption.

Our research is among the first to study the impact of e-book technology on competition in the book industry and to examine the competition in the e-book platform market. This analysis not only provides strategic insights for managers in the book industry but also implications for managers in the whole multimedia industry, which is undergoing the digital transformation. New business models are emerging, and entrants are threatening incumbents’ market position and survival. More research is needed to explore incumbents' survival strategies as well as new comers' winning strategies. While the agency content pricing model is currently widely adopted, it is also interesting to examine the wholesale pricing, in which the platforms determine the content prices as well. The U.S. Justice Department has filed an antitrust lawsuit against Apple and five publishers, accusing them of colluding to fix e-book prices by enforcing the agency pricing model, which charges the same e-book price on all platforms. A comparison between the agency and the wholesale pricing models enables us to further evaluate the impacts of content pricing practice on the e-book market and the e-book platform competition and to provide policy guideline through the total social welfare analysis. Another direction for future research is to look into platforms’ compatibility decision and its impact on competition. 


\section{References}

Armstrong, M. Competition in two-sided markets.The Rand Journal of Economics, 37, 3, 2006, 668-691.

Caillaud, B., and Jullien, B. Chicken \& egg: competition among intermediation service providers. The Rand Journal of Economics, 34, 2, 2003, 309-328.

Conner, K.R. Obtaining strategic advantage from being imitated: when can encouraging “clones” pay? Management Science, 41, 2 (1995), 209-225.

Economides, N. and Katsamakas, E. Two-sided competition of proprietary vs. open source technology platforms and the implications for the software industry.Management Science, 52, 7 (2006), 1057-1071.

Farrell, J. and Saloner, G. Installed base and compatibility: predation, product preannouncements and innovation. The American Economic Review, 76, 5 (1986), 940-955.

Galante, J., and Boudway, I. Amazon doubles down on the Kindle. Business Week, August 2-8, 2010.

Hagiu, A. Pricing and commitment by two-sided platforms.The Rand Journal of Economics, 37, 3, 2006, 720-737.

Jiang, Y. and Katsamakas, E. Impact of e-book technology: ownership and market asymmetries in digital transformation. Electronic Commerce Research and Application, 9, 5 (2010), 386-399. Katz, M.L. and Shapiro, C. Network externalities, competition, and compatibility.The American Economic Review, 75, 3 (1985), 424-440.

Katz, M.L. and Shapiro, C. Technology adoption in the presence of network externalities.Journal of Political Economy, 94 (1986), 822-841. 
Oestreicher-Singer, G., and Sundararajan, A.Are digital rights valuable? Theory and evidence from ebook pricing.Working paper, NYU CeDER-06-01, 2006.

Parker, G., and Van Alstyne, M. Two-sided network effects: a theory of information produce design. Management Science, 51, 10, 2005, 1494-1504.

Peers, M. The high cost of a cheap kindle. Wall Street Journal, July 30, 2010.

Rochet, J.C. and Tirole, J. Platform competition in two-sided markets. Journal of European Economic Association, 1, 4 (2003), 990-1029.

Rochet, J.C. and Tirole, J. Two-sided markets: a progress report. Rand Journal of Economics, 37, 3 (2006), 645-667.

Sporkin, A. Popularity of books in digital platforms continues to grow. Association of American Publishers, published on April 14, 2011, available at: http://www.publishers.org/press/30/.

Trachtenberg, J.A., and Bray, C. Pricing of e-books draws increased antitrust scrutiny. Wall Street Journal, August 3, 2010.

Trachtenberg, J.A. Random House alters e-book pricing strategy. Wall Street Journal, March 1, 2011

Xie, J. and Sirbu, M. Price competition and compatibility in the presence of positive demand externalities.Management Science, 41, 5 (1995), 909-926.

"Digital Media: Digits / Insights from WSJ.Com." Wall Street Journal, May 202011.

\section{Appendix: Proofs}

Proof of Proposition 1: By backward induction, we first solve the pricing equilibrium in the device market, given the per unit content price $P_{c}$ and content sizes $N_{1}$ and $N_{2}$. The profit functions for the two platforms are described in equations (3) and (4). It is straightforward to 
show that each platform's profit function is concave in its own price. Solving the following two first-order conditions (FOCs):

$P_{2} q_{1}-2 P_{1} q_{2}+\left(c_{1}-d_{1}\right) q_{2}+\alpha q_{1} q_{2}\left(N_{1}-N_{2}\right)=0$

$P_{1}-2 P_{2}+\left(c_{2}-d_{2}\right)+q_{2}-q_{1}+\alpha\left(q_{1} N_{1}-N_{2} q_{2}\right)=0$

where $d_{1}=r P_{c} g\left(N_{1}\right)$ and $d_{2}=r P_{c} g\left(N_{2}\right)$,we canderive the equilibrium device prices at a given $P_{c}$ as:

$P_{1}=\left[\left(c_{2}-d_{2}\right) q_{1}+2\left(c_{1}-d_{1}\right) q_{2}+q_{1}\left(q_{2}-q_{1}\right)+\alpha q_{1}\left(2 q_{2} N_{1}-q_{1} N_{1}-q_{2} N_{2}\right)\right] /\left(4 q_{2}-q_{1}\right)$,

$P_{2}=\left[\left(c_{1}-d_{1}\right) q_{2}+2\left(c_{2}-d_{2}\right) q_{2}+2 q_{2}\left(q_{2}-q_{1}\right)+\alpha q_{2}\left(2 q_{2} N_{2}-q_{1} N_{1}-q_{1} N_{2}\right)\right] /\left(4 q_{2}-q_{1}\right)$.

Because the equilibrium device prices are a function of the content price, we next take them back into equation (2), the publishers' profit function, to derive the optimal content price. As equation (2) is concave in $P_{c}$, solving the FOC, we have the equilibrium content price as $P_{c}^{*}=\left[g\left(N_{1}\right) q_{2} T_{1}+g\left(N_{2}\right) q_{1} T_{2}\right] / T_{3}$, with $T_{1}=c_{2} q_{1}+c_{1} q_{1}-2 c_{1} q_{2}+q_{1}\left(q_{2}-q_{1}\right)+$ $\alpha q_{1}\left(2 q_{2} N_{1}-q_{1} N_{1}-q_{2} N_{2}\right), T_{2}=c_{1} q_{2}+c_{2} q_{1}-2 c_{2} q_{2}+2 q_{2}\left(q_{2}-q_{1}\right)+\alpha q_{2}\left(2 q_{2} N_{2}-\right.$ $\left.q_{1} N_{1}-q_{1} N_{2}\right)$, and $T_{3}=4 b q_{1}\left(q_{2}-q_{1}\right)\left(4 q_{2}-q_{1}\right)-2 r\left[\left(2 q_{2}-q_{1}\right)\left(g^{2}\left(N_{1}\right) q_{2}+g^{2}\left(N_{2}\right) q_{1}\right)-\right.$ $\left.2 g\left(N_{1}\right) g\left(N_{2}\right) q_{1} q_{2}\right]$

Last, we take the optimal content price into equations (A3) and (A4), and through simplification we have the equilibrium device prices and demands given in Proposition 1.Note that we present the equilibrium device prices and market demands in the simpler forms containing the optimal content price $P_{c}^{*}$ (which is in the $d_{i}^{*}$ term).

The requirement for $\tilde{\theta}>\theta_{i}$ can be translated into $P_{2} q_{1}-P_{1} q_{2}+\alpha q_{1} q_{2}\left(N_{1}-N_{2}\right)>0$, which is satisfied following equation (A1). The platform market condition $P_{i} \geq c_{i}$ such that both 
platforms exist implies the following parameter conditions: $T_{1} \geq 2 d_{1}^{*} q_{2}+d_{2}^{*} q_{1}$ and $T_{2} \geq 2 d_{2}^{*} q_{2}+d_{1}^{*} q_{2}$. For the content market to be profitable that implies $T_{3}>0$. We assume these parameter conditions hold throughout the paper. $\quad$ Q.E.D.

Proof of Proposition 2: First, we consider the impact of market parameters on the content price. To simplify the notation, we assume that the content sizes $N_{1}$ and $N_{2}$ are big such that $g\left(N_{1}\right) \approx$ $g\left(N_{2}\right)=g$. Given the optimal content price described in Proposition 1, we find the following:

$$
\begin{aligned}
& \frac{\partial P_{c}}{\partial \alpha}=\frac{q_{1} q_{2} g\left(2 q_{2} N_{1}+q_{2} N_{2}-2 q_{1} N_{1}\right)}{T_{3}}>0 ; \frac{\partial P_{c}}{\partial b}=-4 q_{1}\left(4 q_{2}-q_{1}\right)\left(q_{2}-q_{1}\right) \frac{P_{c}}{T_{3}}<0 ; \\
& \frac{\partial P_{c}}{\partial c_{1}}=\frac{2 q_{2} g\left(q_{1}-q_{2}\right)}{T_{3}}<0 ; \frac{\partial P_{c}}{\partial c_{2}}=\frac{q_{1} g\left(q_{1}-q_{2}\right)}{T_{3}}<0 ; \text { and } \frac{\partial P_{c}}{\partial r}=\left(q_{2}-q_{1}\right)\left(2 q_{2}+q_{1}\right) g^{2} \frac{P_{c}}{T_{3}}>0 .
\end{aligned}
$$

Next, we consider the impact of market parameters on platform prices and find the following:

$$
\begin{aligned}
& \frac{\partial P_{1}}{\partial b}=\frac{-r g\left(2 q_{2}+q_{1}\right)}{4 q_{2}-q_{1}} \frac{\partial P_{c}}{\partial b} ; \frac{\partial P_{2}}{\partial b}=\frac{-3 q_{2} r g}{4 q_{2}-q_{1}} \frac{\partial P_{c}}{\partial b} ; \text { and } \frac{\partial P_{2}}{\partial b}>\frac{\partial P_{1}}{\partial b}>0 ; \frac{\partial P_{1}}{\partial r}=\frac{-r g\left(2 q_{2}+q_{1}\right)}{4 q_{2}-q_{1}} \frac{\partial P_{c}}{\partial r} ; \\
& \frac{\partial P_{2}}{\partial r}=\frac{-3 q_{2} r g}{4 q_{2}-q_{1}} \frac{\partial P_{c}}{\partial r} ; \text { and } \frac{\partial P_{2}}{\partial r}<\frac{\partial P_{1}}{\partial r}<0 ; \frac{\partial P_{1}}{\partial c_{1}}=\frac{q_{2}\left[4 b q_{1}\left(4 q_{2}-q_{1}\right)-r g^{2}\left(2 q_{2}+q_{1}\right)\right]}{\left(4 q_{2}-q_{1}\right)\left[2 b q_{1}\left(4 q_{2}-q_{1}\right)-r g^{2}\left(2 q_{2}+q_{1}\right)\right]} ; \\
& \frac{\partial P_{2}}{\partial c_{2}}=\frac{q_{2}\left[8 b q_{1}\left(4 q_{2}-q_{1}\right)-r g^{2}\left(8 q_{2}+q_{1}\right)\right]}{2\left(4 q_{2}-q_{1}\right)\left[2 b q_{1}\left(4 q_{2}-q_{1}\right)-r g^{2}\left(2 q_{2}+q_{1}\right)\right]} \text {; and } 0<\frac{\partial P_{2}}{\partial c_{2}}<\frac{\partial P_{1}}{\partial c_{1}} \text {. The sign for } \frac{\partial P_{i}}{\partial c_{i}} \text { can be }
\end{aligned}
$$

derived from the parameter condition $T_{3}>0$. Q.E.D.

Proof of Proposition 3: When the content sizes $N_{1}$ and $N_{2}$ are big such that $g\left(N_{1}\right) \approx g\left(N_{2}\right)=g$, we find that changes in content sizes $\left(N_{1}, N_{2}\right)$ have the following impacts: 


$$
\begin{aligned}
& \frac{\partial P_{c}}{\partial N_{1}}=2 \frac{\partial P_{c}}{\partial N_{2}}=\frac{2 \alpha q_{1} q_{2} g\left(q_{2}-q_{1}\right)}{T_{3}}>0 ; \frac{\partial D_{c}}{\partial N_{1}}=2 \frac{\partial D_{c}}{\partial N_{2}}=\frac{\alpha q_{2} g}{\left(4 q_{2}-q_{1}\right)}>0 ; \\
& \frac{\partial D_{1}}{\partial N_{1}}=\frac{\alpha q_{2}\left[4 b q_{1}\left(4 q_{2}-q_{1}\right)\left(2 q_{2}-q_{1}\right)-2 r g^{2}\left(2 q_{2}^{2}+2 q_{1} q_{2}-q_{1}^{2}\right]\right.}{T_{3}\left(4 q_{2}-q_{1}\right)}>0 ; \\
& \frac{\partial D_{2}}{\partial N_{2}}=\frac{\alpha q_{2}\left[4 b q_{1}\left(4 q_{2}-q_{1}\right)\left(2 q_{2}-q_{1}\right)-r g^{2}\left(8 q_{2}^{2}-q_{1} q_{2}-q_{1}^{2}\right]\right.}{T_{3}\left(4 q_{2}-q_{1}\right)}>0 \text { and } \frac{D_{1}}{N_{1}}>\frac{D_{2}}{N_{2}} ; \\
& \frac{\partial D_{1}}{\partial N_{2}}=\frac{-\alpha q_{2}^{2}\left[4 b q_{1}\left(4 q_{2}-q_{1}\right)-6 r g^{2} q_{2}\right]}{T_{3}\left(4 q_{2}-q_{1}\right)}<0 ; \frac{\partial D_{2}}{\partial N_{1}}=\frac{-\alpha q_{1} q_{2}\left[4 b q_{1}\left(4 q_{2}-q_{1}\right)-6 r g^{2} q_{2}\right]}{T_{3}\left(4 q_{2}-q_{1}\right)}<0 \text { and } \\
& \frac{D_{1}}{N_{2}}<\frac{D_{2}}{N_{1}} ; \frac{\partial\left(D_{1}+D_{2}\right)}{\partial N_{1}}=2 \frac{\partial\left(D_{1}+D_{2}\right)}{\partial N_{2}}=2 \alpha q_{2} \frac{4 b q_{1}\left(4 q_{2}-q_{1}\right)\left(q_{2}-q_{1}\right)-r g^{2}\left(2 q_{2}^{2}-q_{1} q_{2}-q_{1}^{2}\right.}{\left(4 q_{2}-q_{1}\right) T_{3}}>0 ; \\
& \frac{\partial \pi_{c}}{\partial N_{i}}=(1-r)\left(P_{c} \frac{\partial D_{c}}{N_{i}}+D_{c} \frac{\partial P_{c}}{N_{i}}\right)>0 \text { with } P_{c} \frac{\partial D_{c}}{N_{i}}=D_{c} \frac{\partial P_{c}}{N_{i}} \text { and } \frac{\partial \pi_{c}}{\partial N_{1}}=2 \frac{\partial \pi_{c}}{\partial N_{2}}>0 . \text { Q.E.D. }
\end{aligned}
$$




\title{
NET Institute*
}

\section{Www.NETinst.org}

Working Paper \#12-19

September 2012

e-Book Platform Competition in the Presence of Two-Sided Network Externalities

\author{
Yabing Jiang \\ Florida Gulf Coast University \\ Lutgert College of Business
}

* The Networks, Electronic Commerce, and Telecommunications ("NET") Institute, http://www.NETinst.org, is a non-profit institution devoted to research on network industries, electronic commerce, telecommunications, the Internet, "virtual networks" comprised of computers that share the same technical standard or operating system, and on network issues in general. 